\title{
Lean Construction in Civil Engineering and Project Management: Case Study Analysis of UT Arlington College Park
}

\author{
Ashwin Amarshi Maru \\ L.E.College, Civil engineering department, Saurashtra University, Rajkot, State: Gujarat, India
}

Email address:

maru.ashvin@gmail.com

To cite this article:

Ashwin Amarshi Maru. Lean Construction in Civil Engineering and Project Management: Case Study Analysis of UT Arlington College Park. American Journal of Civil Engineering. Vol. 3, No. 3, 2015, pp. 70-74. doi: 10.11648/j.ajce.20150303.13

\begin{abstract}
Lean development method, which has been applied extensively in the manufacturing industry, holds enormous potential for the construction industry as well. Projects in the construction segments are complex with both financial level and work level risks. This research critically analyzes the benefits in using lean methods in construction. The lean construction management called the Last Planner System is applied here. The research uses a case study methodology, the case study of UT Arlington College Park Constructions are selected. The Last Planner system and its techniques are applied to Case Study. The benefits of the Last Planner implementation are proved by the recorded PPC value before and after implementation of the last planner system. The PPC values increased. This research concludes that Last Planner system must be further investigated for benefits in Civil Engineering and Project Management, and also recommends it use in Construction Projects.
\end{abstract}

Keywords: Lean Construction, Last Planner System, LPS, Production Management, Project Management, PPC

\section{Introduction}

The Construction Industry is one of the most rapidly evolving sectors in Civil Engineering. The Projects are quite large in terms of the outputs needed to be produced and the budgets and time are very stringent as well. In this context the stress applied in terms of the project managers on completing the contract or project within time and within budget constraints are enormous. This study investigates the application of lean construction methodology-the last planner system on construction projects so as to increase efficiency of these projects and also to increase the benefits on the project management end.

Management of projects in the construction industry is a task of immense magnitude. The projects itself are big, and in addition the task divisions and more that are being assigned are also quite complex in itself. Researchers cite that the construction industry is one that suffers huge financial setbacks based on time element. In this context it becomes extremely necessary that the industry have an efficient way to manage its tasks such that productivity is increased and at the same time the project management process also becomes efficient [1]. This is because one might not exist without the other. Project management starts from project procurement tasks, to efficient collation of material and men, developing collaborations between the various project units, arranging systematic task flow towards project completion, managing interdependencies, managing resources, specifying project durations, buffer, critical mean paths and more. Koskela argues that the construction industry and its wasteful practices are creating many struggles with all the stakeholders involved. This was also the time as indicated in literature, when the construction industry started taking strategic hints and planning systems from the manufacturing industry (Koskela, L. 1992).

Lean Technology is a defined technology that is currently being practiced in the workplace and that which simplifies project management tasks and increased productivity in the workplace. Lean technology professes the need for documentation and usage of visualization tools in order to improve process efficiency. This simple documentation and accountability will enable the processes to become more effective. It was a component of manufacturing industry and is now adapted for the construction industry [4]. It derives its production planning and control processes from the manufacturing segment. 


\section{Research Background}

Lean Construction is a novel way in civil engineering. It is a combination of the most adaptable lean construction practices. By lean construction practices the meaning denoted here is that the end to end design becomes more cost effective and productive. It is a process adaptation from the manufacturing industry when the manufacturing industry went into its decline. The manufacturing industry according to Koskela was argued as being ridden with wasteful practices and struggles. This was creating detrimental effects on the organizations and also the people involved [6]. It was in this context that lean technology was arrived at. Lean technology is more a philosophy and a set of principles that was rooted in the manufacturing sector.

There was much complexity in the adoption of lean construction techniques from its counterpart in manufacturing. In the construction industry the end products are not being transported directly to the final users, here the product or onsite production is regulated in a fixed site. The value of the construction project is increased on site, so it is necessary that the contractor equipments and more are to be installed and coordinated for work, at the site. Secondly in the case of production there are many components that come together into production, still since the manufactory unit is quite large, it is necessary to customize the equipment for some standard component manufactory [11]. On the other hand in the case of the construction industry it is seen that the construction industry consumers will play a big role in the project cycle. Customizations are possible to a great extent and the owner of the project will be able to modify the project based on some individual requirements (Adamu \& Hamid, 2012).

Thirdly the complexity that is introduced in the case of the manufacturing and the construction industry is also quite different. In the case of the manufacturing industry the suppliers are usually selected quite early, they are then utilized based on the necessary strategic advantages. Reliable flow of the product that is manufactured is hence assured. On the other hand in the case of construction projects it is seen that the projects are usually quite complex. The systems that are involved are very dynamic and although a plan is in place it become necessary that the plan be adjusted based on some of parameters at site. There are overlapping activities of the constructors which furthermore increases the complexity (Adamu \& Hamid, 2012). These differences have to be taken into account when the lean production process is applied to construction. It is this very complexity that warrants the need for a construction technique that will be efficient for the worksite. Lean construction as argued by Koskela et al is hence a system that will be able to work with the complexity in the site and still be able to minimize the wastage. The system to hence implement lean construction is possible only with the collaboration of the Owner, A/E, Constructors, Facility Managers, and End-users for the project. In addition the respective on site extra managers, facility managers and more will be included in the process.
The Last planner is a lean construction technique and as such incorporates the benefits of lean construction methodology. It is a technique which "Last Planner is part of a new production management system for one-off projectbased production such as that in construction and design. This business strategy allows project managers to significantly improve productivity and client/end-user satisfaction when compared to the equally consistent old way of doing business" (p.6) [8].

\section{Literature Review}

The complexity in construction is increased because of the need for coordination among participants, the materialprocess flow adequacy and the architecture production concerns. This complexity easily leads to financial losses. The Lean technology system might help remedy these issues by solving potential problems in construction beforehand (Lichtig 2004). Lean technology has one major principle it is discarding of the waste and enhancing profits in that process. The lean technology is the emerging innovative technology that will address all the redundancy in the processes and enable companies to come up with new innovative solutions for the current times. As Lichtig (2004) presents, the production process design can be implemented using lean production principles that will help manage issues based on the information inputs that are created from diverse human resource ends. It will not only be the higher level management, but also site foreman, managers and more that will be involved and hence a wide range of solutions can be arrived at for these issues.

Management efficiency is a concept that is touched upon by authors dealing with lean construction principles. Melhado (1998) identifies the principles that could serve as guidelines for lean construction in the workplace. These principles as argued by Melhado are built on the exact reasons that traditional construction techniques fail [7]. One of the primary reasons for failure as suggested by Melhado is that, the traditional approach relies heavily on the decision making of the management. The traditional management does not cater to the emerging needs of the end user, monetary concerns changes with each project and the current companies need to face up to the challenges brought on by the competitors. There is an inherent need to bring a new paradigm shift from traditional practices. This also emphasis the need for new innovative practices like the Lean technology these issues leads to management deficiency issues in civil engineering. These same issues are also the major reason for the construction industry being reluctant to take up newer practice such as lean construction [7]. A similar approach to expounding on the benefits of lean construction technique in project management and construction sector has been presented by researcher Suresh et al (2012). Here they state management awareness to be the issue. In the adoption of lean technology such as the last planner system, the management comes into contact with the people that they work with on a daily basis. Daily Huddle 
style meetings assure this.

By adopting Lean technology the companies are able to add more visualization elements into their project planning and implementation. These visual aids assist in creating of Commitment chart, Mobile signs and project markers. Owing to these visual elements accurate depiction of the elements and increased accountability of the processes is created [2]. By implementing lean technology visualization tools the companies are able to stay within budget and adopt robust innovative techniques in the process

Huddle meetings are proposed in this process. This is very different from conventional official conferences. The foremen all gather around and discuss the issues for a maximum of ten minutes before the start of their construction work. This saves time. Apart from these meetings continual assessment is done at regular intervals. This enables the quality of the deliverables at each stage in the construction process. A preliminary examination, which is done in the beginning, is used to determine the processes that require a large amount of resources and costs [3]. Then innovative ideas to reduce any wastage in the existing process are discussed. This is known as First run Studies process. This is a process in lean technology that reduces waste.

By adopting the lean technology process the construction industry needs to follow five main factors [10]. They are categorization of the materials, straightening of the materials, development of standardization of the material layout; clustering the zone of work. When these factors are followed in every step of the process high quality of deliverables is ensured.

The efficacy of the lean technology process is largely dependent on the people implementing and the people following it. This technology is only a tool and it depends on the developer of the plan to ensure that it is robust and innovative. The plan development using lean technology is dependent on numerable factors to name some they are the geographical factors, the size of the project, the cost involved for the project, foremen, contractors, sub-contractors and all the stakeholders involved in the project and the cultural practices of the place [6] Based on these factors the lean technology plan will differ. It has been observed that there has been an overall improvement in all of the processes involved by adopting lean technology.

Mossman explains that "Last Planner" is an important tool of the Lean contruction technique. Last Planner is also acknowledged as "Reverse Phase Scheduling". It is used to remove the redundancy of the processes and enables timely delivery of the projects and the projections are pragmatic. It is also used as a predictive tool that foresees the issues beforehand. The Variance plan and the Percentage Plan finalized plans can be generated from this tool. Weekly Work Plan( WWP) is also done in this process. As the name suggests it is documentation that is done on a weekly basis. This aided in increasing of the accountability and easy idenitification of the anomalies that existed in the system. Mossman presents some of the key benefits of the last planner that will be useful for both civil engineering projects and project management are:

1. It helps in the decentralization of the planning in an organization. Most often organizations push the process of decision making on the management end. While this is the classical approach, in construction industry this leads to a waste in time and available resource management. However where a decentralization supportive tool like the Last Planner is used, then the trade foremen, site men and design-team leaders are all provided with the authority and space required to make instant decisions based on the work site requirements [8]. This not only improves the human resources but also helps increase productivity and improved crises management.

2. CPM is no longer the best way to manage a program as the Critical Path planning system is more predominantly a push form of system [9]. It pushes work into production. The CPM scheduler uses the predetermined dates for the start of the project and the completion of the project in order to measure progress for the work. However the push measure fails because of the assumptions made on the work done and the plan [8]. People assume that other people are working according to the plan, however what should be done and what is being done are not always that matched. A ceiling contractor might end up working on the ceilings before the $\mathrm{M} \& \mathrm{E}$ contractor finishes their work above them. The work therefore become guess work, and while some guesses are spot on, others might not be leading to disastrous prodcutivity consequences.

3. Last Planner System LPS has the potential to reduce the stress that is being created on the management staff. Project Management Staff ad the advisory staff are usually under tremendous stress when they have to stay engaged with the deadlines, the last planner system helps the Project management stay spot on with the deadlines and at the same time reduces the risks at the workplace so as to increasing the workplace productivity [8].

4. Last planner tool does not look at issues from a unilateral viewpoint rather it encompasses a number of different issues while generating the results thereby adopting a comprehensive approach while providing solutions.

5. The realistic approach to the solutions that this tool provides is the preeminent feature of this tool.

6. The methodology used here is a case study approach. The case study approach is a predominantly qualitative research, which has been used here so as to investigate the application of lean construction methodology-the last planner system on construction projects and its efficiency in increasing benefits to project management.

The case study approach has been used here as it helps in the investigation of a phenomenon where multiple variables of interest are being studied. The Last planner system application to a case study system, helps understand the benefits that it brrought to the system. In this research the 
Last Planner system application to the construction project in UT Arlington College Park located on the University of Texas at Arlington Campus is studied. The framework followed by the research article is presented below.

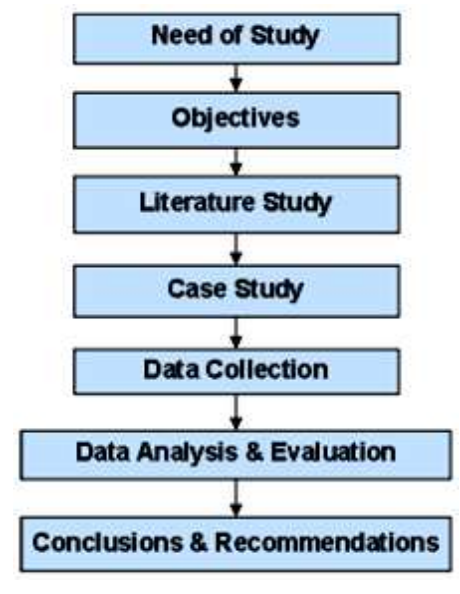

Figure 1. Research Method

\section{Case Study: Data Analysis and Discussion}

The Last Planner system was implemented a project with UT Arlington College Park. Estimated at a value of US \$ 65 million, the project involved the completion of three multistory parking garages with car capacity of 1800 , residential halls amounting to around 500, central welcome center and sports allotments. To be completed in two phases, Phase 1 was to take a time period of 12 months, while the second was to be completed in 13 months.

Percent Part Complete (PPC) values were calculated as a measure of the workflow reliability.

$$
\text { Percent Part Complete (PPC) } \%=\frac{\text { Number of completed assigned activities for the project }}{\text { Total number of activities defined for the compleation of project }} X 100
$$

The calculations for the system indicate that the Percent Part Complete (PPC) had improved by more than $60 \%$ in the first week, and was at $88 \%$ in $4^{\text {th }}$ week and around $83 \%$ at the end of the 17 weeks. This gave an average value of $73 \%$, which was higher than the $60 \%$ achieved at Phase 1 . The PPC ration for Phase 1 also increased only after the inclusion of the Last Planner system.

Below given table summarizes the project details.

Table 1. Summary of Project Details

\begin{tabular}{|c|c|c|c|c|}
\hline $\begin{array}{l}\text { Project } \\
\text { Phase }\end{array}$ & $\begin{array}{l}\text { Value of } \\
\text { Contract }\end{array}$ & $\begin{array}{l}\text { Approx. Time of } \\
\text { completion }\end{array}$ & $\begin{array}{l}\text { \% Time elapsed when the Last } \\
\text { Planner System Implemented }\end{array}$ & $\begin{array}{l}\text { Subcontractors involved in the last } \\
\text { planner system implementation }\end{array}$ \\
\hline \multicolumn{5}{|c|}{ UT Arlington College Park located on the University of Texas at Arlington Campus } \\
\hline Phase - I & & 12 Months & $80 \%$ & None \\
\hline Phase - II & US \$ 65 Million & 13 Months & $0 \%$ & $\begin{array}{l}\text { Mechanical } \\
\text { Architectural } \\
\text { Structural } \\
\text { Electrical } \\
\text { Plumbing }\end{array}$ \\
\hline
\end{tabular}

The last planner implementation activity was completed in four stages. Stage 1 was allotted for workshop and observations on current practice and this was also the period where the Project Manager level discussions were conducted. The Second stage involved the Pull planning phase with the look ahead planning (a critical component of Last Planner). Reverse scheduling of the process is also done at this stage. This backward process was then visually depicted using the Gantt chart. Gantt Chart was developed for each building in the projects. Gantt Chart was developed by asking the inputs of the stakeholders in the construction. This enabled the analysts to find out the redundant processes and the processes that require high costs and time. This enabled a reduction of wastage. This step increases accountability of the process and also enables in determining the project in realistic conditions. The Third stage involved the short terms weekly planning. The Third stage is actually the longest stage of the processes. For this project this stage took about 17 weeks. It uses the short-term weekly planning compares it with the PPC. This helps in repetitive evaluation of the processes that are occurring. From this any discrepancy in the process or any issues can be determined in the preliminary phase of the issues and can be rectified. Any process, which was not completed within the preceding week, was carried over to the next and successfully completed in the current week. This enabled easy rectification of the issues. It was observed that by adopting this technique there was better performance in all the relevant processes. This benefited the contractors, companies and all the other stakeholders involved in this process. The final stage was the evaluation of the Last Planner system. For the evaluation the people involved in the actual processes was questioned orally and the people were also asked predefined questions in the form of survey questionnaire. This evaluation technique enabled the companies to identify the vulnerable areas. The problem areas was identified and rectified. The people were also questioned about their inputs. This would aid the future projects greatly. This is an important final stage, which 
allows the stakeholders to retrospect. All the four stages were given equal importance.

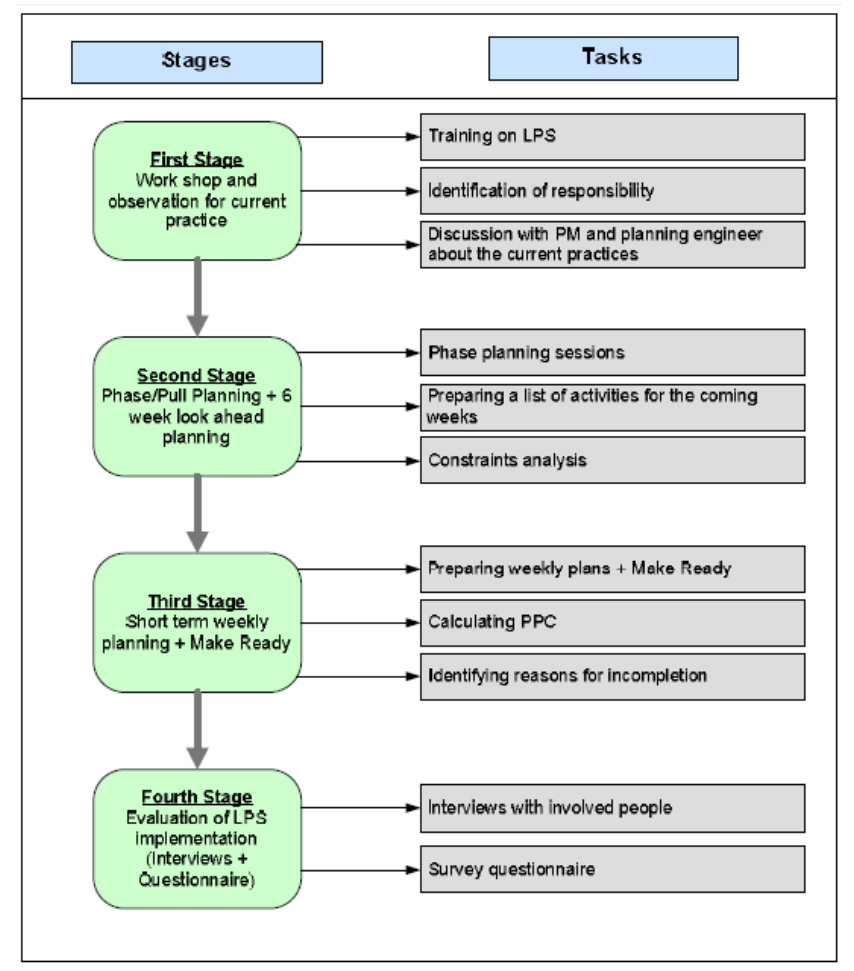

Figure 2. The Last Planner System Implementation Strategy, UT Arlington College Park located on the University of Texas at Arlington Campus. (Source: Garza, and Leong, 2000) [5]

\section{Conclusion}

The improvement of the PPC values indicates that the project performance improved with time. This improvement was noted after the Last Planner system which is a lean construction system was implemented in the Phase 1 and 2 of the projects. The case study hence indicates that the Last Planner system is able to improve efficiency in productivity. In improving project management processes by means of individually planned phases and look ahead weeks it also helps reduce the stress on project managers and hence is vital to construction project management. It should be noted that the last planner system does not focus on the issues from a unilateral angle rather it takes into account a multitude of factors thereby improving the processes. Also the documentation of events and process has greatly improved the accountability.

\section{References}

[1] Adamu, S., Hamid, R, A. (May 2012), Lean Construction Techniques Implementation in Nigeria Construction Industry, Canadian Journal on Environmental, Construction and Civil Engineering, 3(4), 186-193

[2] Arditi, D., and Gunaydin, H. (1997) Total quality management in the construction process." Int. J. Proj. Manage., 15(4), 235-243.
[3] Ballard, G. (1994). The Last Planner. Spring Conference of the Northern California Construction Institute, Monterey, CA, April 22-24.

[4] Ballard, G., \& Tommelein, I. (2012). Lean management methods for complex projects. Engineering Project Organization Journal, 2(1-2), 85-96.

[5] Ballard, G. (1997). Look ahead Planning: The Missing Link in Production Control, Proc. $5^{\text {th }}$ Annual Conf. Int'l. Group for Lean Constr., IGLC 5, July, Gold Coast, Australia, 13-26.

[6] Garza, J. M. D. L., and Leong, M. (2000). "Last planner technique: A case study." Construction

[7] Koskela, L. (September, 1992), Application of the New Production Philosophy to Construction, CIFE Technical Report, 72, 1-75.

[8] Melhado, S, B. (1998), Designing for Lean Construction, Proceedings IGLC.

[9] Mossman, A. (2013). Last Planner: $5+1$ crucial \& collaborative conversations for predictable design \& construction delivery. The Change Business Limited

[10] Rother, M \& Shook, J, 2003, Learning to See, Lean Enterprise Institute Inc., USA

[11] Salem, O.,Solomon, J.,Genaidys, A. \& Minkarah, I. (October, 2006), Lean Construction: From Theory to Implementation., Journal of Management in Engineering, 168-175, Birmingham.

[12] Dave, B., Koskela, L., Kiviniemi, A., Tzortzopoulos, P., \& Owen, R. L. (2013). Implementing lean in construction: lean construction and BIM.

[13] Garza-Reyes, J. A., Parkar, H. S., Oraifige, I., Soriano-Meier, H., \& Harmanto, D. (2012). An empirical-exploratory study of the status of lean manufacturing in India. International Journal of Business Excellence, 5(4), 395-412.

[14] Gao, S., \& Low, S. P. (2014). The Toyota Way model: an alternative framework for lean construction. Total Quality Management \& Business Excellence, 25(5-6), 664-682.

[15] Howell, G. A. (1999, July). What is lean construction-1999. In Proceedings IGLC (Vol. 7, p.

[16] Koskela, L. (1997). Lean production in construction. Lean construction, 1-9.

[17] Melles, B. E. R. T. (1997). What do we mean by lean production in construction. Lean Construction, 24-29

[18] Ohno, T, (1988), Toyota Production System: Beyond Large Scale Production, Productivity Press, New York.

[19] Sarhan, S., \& Fox, A. (2013). Barriers to implementing lean construction in the UK construction industry. The Built \& Human Environment Review, 6.

[20] Tommelein, I. D. (2015). Journey toward Lean Construction: Pursuing a Paradigm Shift in the AEC Industry. Journal of Construction Engineering and Management. 